\title{
Some new common coupled fixed point results in two generalized metric spaces
}

Feng $\mathrm{Gu}^{*}$

\author{
"Correspondence: \\ gufeng99@sohu.com \\ Institute of Applied Mathematics \\ and Department of Mathematics, \\ Hangzhou Normal University, \\ Hangzhou, Zhejiang 310036, China
}

\author{
Abstract \\ The purpose of this paper is to extend some recent common coupled fixed point \\ theorems in two G-metric spaces in an essentially different and more natural way. We \\ also provide illustrative examples in support of our new results. \\ MSC: $47 \mathrm{H} 10 ; 54 \mathrm{H} 25$ \\ Keywords: common coupled fixed point; coupled coincidence point; \\ $w^{*}$-compatible mapping pairs; generalized metric space
}

\section{Introduction and preliminaries}

In 2006, Mustafa and Sims [1] introduced a new structure of generalized metric spaces, which are called $G$-metric spaces, as follows.

Definition 1.1 [1] Let $X$ be a nonempty set, and let $G: X \times X \times X \longrightarrow R^{+}$be a function satisfying the following axioms:

(G1) $G(x, y, z)=0$ if $x=y=z$;

(G2) $0<G(x, x, y)$ for all $x, y \in X$ with $x \neq y$;

(G3) $G(x, x, y) \leq G(x, y, z)$ for all $x, y, z \in X$ with $z \neq y$;

(G4) $G(x, y, z)=G(x, z, y)=G(y, z, x)=\cdots$ (symmetry in all three variables);

(G5) $G(x, y, z) \leq G(x, a, a)+G(a, y, z)$ for all $x, y, z, a \in X$ (rectangle inequality).

Then the function $G$ is called a generalized metric or a $G$-metric on $X$ and the pair $(X, G)$ is called a $G$-metric space.

It is known that the function $G(x, y, z)$ on a $G$-metric space $X$ is jointly continuous in all three of its variables, and $G(x, y, z)=0$ if and only if $x=y=z$ (see [1]).

Based on the notion of generalized metric spaces, Mustafa et al. [1-6] obtained some fixed point results for mappings satisfying different contractive conditions. Chugh et al. [7] obtained some fixed point results for maps satisfying property $P$ in $G$-metric spaces. Shatanawi [8] obtained some fixed point results for contractive mappings satisfying $\Phi$ maps in G-metric spaces.

In 2009, Abbas and Rhoades [9] initiated the study of common fixed point theory in $G$-metric spaces. Since then, many common fixed point theorems for certain contractive conditions have been established in G-metric spaces (see [10-19]).

Bhaskar and Lakshmikantham [20] introduced the notion of coupled fixed point and proved some interesting coupled fixed point theorems for mappings satisfying the mixed monotone property. Later, Lakshmikantham and Ćirić [21] introduced the concept of

(c) 2013 Gu; licensee Springer. This is an Open Access article distributed under the terms of the Creative Commons Attribution License (http://creativecommons.org/licenses/by/2.0), which permits unrestricted use, distribution, and reproduction in any medium, provided the original work is properly cited. 
mixed $g$-monotone mapping and proved coupled coincidence and coupled common fixed point theorems that extend theorems due to Bhaskar and Lakshmikantham [20].

In $[22,23]$, authors established coupled fixed point theorems in cone metric spaces. In 2011, Shatanawi [24] obtained some coupled fixed point results in G-metric spaces. Recently, in $[25,26]$ authors established some coupled fixed point and common coupled fixed point results in two G-metric spaces. Recently, coupled fixed point and common coupled fixed point problems have also been considered in partially ordered G-metric spaces (see [27-38]).

The aim of this article is to prove some new common coupled fixed point theorems for mappings defined on a set equipped with two generalized metrics.

First, we present some known definitions and propositions.

Definition 1.2 [1] Let $(X, G)$ be a $G$-metric space, $\left\{x_{n}\right\} \subset X$ be a sequence. Then the sequence $\left\{x_{n}\right\}$ is called:

(i) a G-Cauchy sequence if, for any $\varepsilon>0$, there is an $n_{0} \in \mathbb{N}$ (the set of natural numbers) such that for all $n, m, l \geq n_{0}, G\left(x_{n}, x_{m}, x_{l}\right)<\varepsilon$;

(ii) a $G$-convergent sequence if, for any $\varepsilon>0$, there are an $x \in X$ and an $n_{0} \in \mathbb{N}$ such that for all $n, m \geq n_{0}, G\left(x, x_{n}, x_{m}\right)<\varepsilon$.

A $G$-metric space $(X, G)$ is said to be $G$-complete if every $G$-Cauchy sequence in $(X, G)$ is $G$-convergent in $X$. It is known that $\left\{x_{n}\right\}$ is G-convergent to $x \in X$ if and only if $G\left(x_{m}, x_{n}, x\right) \rightarrow 0$ as $n, m \rightarrow \infty$.

Proposition 1.3 [1] Let $(X, G)$ be a G-metric space. Then the following are equivalent:

(1) $\left\{x_{n}\right\}$ is G-convergent to $x$.

(2) $G\left(x_{n}, x_{n}, x\right) \rightarrow 0$ as $n \rightarrow \infty$.

(3) $G\left(x_{n}, x, x\right) \rightarrow 0$ as $n \rightarrow \infty$.

(4) $G\left(x_{n}, x_{m}, x\right) \rightarrow 0$ as $n, m \rightarrow \infty$.

Proposition 1.4 [1] Let $(X, G)$ be a G-metric space. Then, for any $x, y \in X$, we have $G(x, y, y) \leq 2 G(y, x, x)$.

Definition 1.5 [20] An element $(x, y) \in X \times X$ is called:

$\left(C_{1}\right)$ a coupled fixed point of the mapping $F: X \times X \rightarrow X$ if $F(x, y)=x$ and $F(y, x)=y$;

$\left(C_{2}\right)$ a coupled coincidence point of mappings $F: X \times X \rightarrow X$ and $g: X \rightarrow X$ if $F(x, y)=g x$ and $F(y, x)=g y$, and in this case, $(g x, g y)$ is called a coupled point of coincidence;

$\left(\mathrm{C}_{3}\right)$ a common coupled fixed point of mappings $F: X \times X \rightarrow X$ and $g: X \rightarrow X$ if $F(x, y)=$ $g x=x$ and $F(y, x)=g y=y$.

Definition 1.6 [25] Mappings $F: X \times X \rightarrow X$ and $g: X \rightarrow X$ are called:

$\left(\mathrm{W}_{1}\right) \quad w$-compatible if $g F(x, y)=F(g x, g y)$ whenever $F(x, y)=g x$ and $F(y, x)=g y$;

$\left(\mathrm{W}_{2}\right) w^{*}$-compatible if $g F(x, x)=F(g x, g x)$ whenever $F(x, x)=g x$.

Recently, Abbas, Khan and Nazir [25] extended some recent results of Abbas et al. [22] and Sabetghadam et al. [23] to the setting of two generalized metric spaces.

Theorem 1.7 (see [25, Theorem 2.1]) Let $G_{1}$ and $G_{2}$ be two G-metrics on $X$ such that $G_{2}(x, y, z) \leq G_{1}(x, y, z)$ for all $x, y, z \in X$, and let $F: X \times X \rightarrow X, g: X \rightarrow X$ be two mappings 
satisfying

$$
\begin{aligned}
G_{1}( & F(x, y), F(u, v), F(s, t)) \\
\leq & a_{1} G_{2}(g x, g u, g s)+a_{2} G_{2}(F(x, y), g x, g x) \\
& +a_{3} G_{2}(g y, g v, g t)+a_{4} G_{2}(F(u, v), g u, g s) \\
& +a_{5} G_{2}(F(x, y), g u, g s)+a_{6} G_{2}(F(u, v), F(s, t), g x)
\end{aligned}
$$

for all $(x, y),(u, v),(s, t) \in X \times X$, where $a_{i} \geq 0$, for $i=1,2, \ldots, 6$ and $a_{1}+a_{3}+a_{5}+2\left(a_{2}+\right.$ $\left.a_{4}+a_{6}\right)<1$. If $F(X \times X) \subset g(X)$ and $g(X)$ is a $G_{1}$-complete subspace of $X$, and $F$ and $g$ are $w^{\prime \prime}$-compatible, then $F$ and $g$ have a unique common coupled fixed point.

Theorem 1.8 (see [25, Theorem 2.6]) Let $G_{1}$ and $G_{2}$ be two G-metrics on $X$ such that $G_{2}(x, y, z) \leq G_{1}(x, y, z)$ for all $x, y, z \in X$, and let $F: X \times X \rightarrow X, g: X \rightarrow X$ be two mappings satisfying

$$
\begin{aligned}
& G_{1}(F(x, y), F(u, v), F(s, t)) \\
& \quad \leq k \max \left\{G_{2}(g x, g u, g s), G_{2}(g y, g v, g t), G_{2}(F(x, y), g u, g s)\right\}
\end{aligned}
$$

for all $(x, y),(u, v),(s, t) \in X \times X$, where $0 \leq k<\frac{1}{2}$. If $F(X \times X) \subset g(X)$ and $g(X)$ is a $G_{1}$ complete subspace of $X$, and $F$ and $g$ are $w^{*}$-compatible, then $F$ and $g$ have a unique common coupled fixed point.

In this manuscript, we generalize, improve, enrich and extend the above coupled fixed point results. It is worth mentioning that our results do not rely on the continuity of mappings involved therein. We also state some examples to illustrate our results. This paper can be considered as a continuation of the remarkable works of Abbas et al. [22, 23] and Sabetghadam et al. [25].

\section{Common coupled fixed points}

We begin with an example to illustrate the weakness of Theorem 1.8 above.

Example 2.1 Let $X=[0,1]$. Define $G_{1}, G_{2}: X \times X \times X \rightarrow[0, \infty)$ by

$$
G_{1}(x, y, z)=|x-y|+|y-z|+|z-x| \quad \text { and } \quad G_{2}(x, y, z)=\frac{4}{5}(|x-y|+|y-z|+|z-x|)
$$

for all $x, y, z \in X$. Then $\left(X, G_{1}\right)$ and $\left(X, G_{2}\right)$ are two $G$-metric spaces. Define a map $F: X \times$ $X \rightarrow X$ by $F(x, y)=\frac{1}{16} x+\frac{5}{16} y$ and $g x=\frac{x}{2}$ for all $x, y \in X$. For $(x, y)=(u, v)=(2,0)$ and $(s, t)=$ $(0,2)$, we have

$$
\begin{aligned}
G_{1}(F(x, y), F(u, v), F(s, t)) & =G_{1}(F(2,0), F(2,0), F(0,2)) \\
& =G_{1}\left(\frac{1}{8}, \frac{1}{8}, \frac{5}{8}\right) \\
& =1
\end{aligned}
$$


and

$$
\begin{aligned}
\max & \left\{G_{2}(g x, g u, g s), G_{2}(g y, g v, g t), G_{2}(F(x, y), g u, g s)\right\} \\
& =\max \left\{G_{2}(g 2, g 2, g 0), G_{2}(g 0, g 0, g 2), G_{2}(F(2,0), g 2, g 0)\right\} \\
& =\max \left\{G_{2}(1,1,0), G_{2}(0,0,1), G_{2}\left(\frac{1}{8}, 1,0\right)\right\} \\
& =\frac{8}{5} .
\end{aligned}
$$

Then it is easy to see that there is no $k \in\left[0, \frac{1}{2}\right)$ such that

$$
G_{1}(F(x, y), F(u, v), F(s, t)) \leq k \max \left\{G_{2}(g x, g u, g s), G_{2}(g y, g v, g t), G_{2}(F(x, y), g u, g s)\right\}
$$

for all $(x, y),(u, v),(s, t) \in X \times X$. Thus, Theorem 1.8 cannot be applied to this example. However, it is easy to see that $(0,0)$ is the unique common coincidence point of $F$ and $g$. In fact, $F(0,0)=g(0)=0$.

Now we shall prove our main results.

Theorem 2.2 Let $G_{1}$ and $G_{2}$ be two $G$-metrics on $X$ such that $G_{2}(x, y, z) \leq G_{1}(x, y, z)$ for all $x, y, z \in X$, and let $F: X \times X \rightarrow X, g: X \rightarrow X$ be two mappings satisfying

$$
\begin{aligned}
G_{1}( & F(x, y), F(u, v), F(s, t)) \\
\leq & a_{1} G_{2}(g x, g u, g s)+a_{2} G_{2}(g y, g v, g t)+a_{3} G_{2}(F(x, y), g x, g x) \\
& +a_{4} G_{2}(F(u, v), g u, g u)+a_{5} G_{2}(F(s, t), g s, g s)+a_{6} G_{2}(F(x, y), g u, g s) \\
& +a_{7} G_{2}(F(u, v), g s, g x)+a_{8} G_{2}(F(s, t), g x, g u)+a_{9} G_{2}(F(x, y), g x, g u) \\
& +a_{10} G_{2}(F(u, v), g u, g s)+a_{11} G_{2}(F(s, t), g s, g x)+a_{12} G_{2}(F(x, y), F(u, v), g s) \\
& +a_{13} G_{2}(F(u, v), F(s, t), g x)+a_{14} G_{2}(F(s, t), F(x, y), g u)
\end{aligned}
$$

for all $(x, y),(u, v),(s, t) \in X \times X$, where $a_{i} \geq 0$, for $i=1,2, \ldots, 14$ and

$$
a_{1}+a_{2}+a_{6}+a_{9}+2\left(a_{3}+a_{4}+a_{5}+a_{10}+a_{12}+a_{13}+a_{14}\right)+3\left(a_{7}+a_{8}+a_{11}\right)<1 .
$$

If $F(X \times X) \subset g(X)$ and $g(X)$ is a $G_{1}$-complete subspace of $X$, and $F$ and $g$ are $w^{*}$-compatible, then $F$ and $g$ have a unique common coupled fixed point.

Proof Let $x_{0}, y_{0} \in X$. Since $F(X \times X) \subset g(X)$, we can choose $x_{1}, y_{1} \in X$ such that $g x_{1}=$ $F\left(x_{0}, y_{0}\right)$ and $g y_{1}=F\left(y_{0}, x_{0}\right)$. Similarly, we can choose $x_{2}, y_{2} \in X$ such that $g x_{2}=F\left(x_{1}, y_{1}\right)$ and $g y_{2}=F\left(y_{1}, x_{1}\right)$. Continuing in this way, we construct two sequences $\left\{x_{n}\right\}$ and $\left\{y_{n}\right\}$ in $X$ such that

$$
g x_{n+1}=F\left(x_{n}, y_{n}\right) \quad \text { and } \quad g y_{n+1}=F\left(y_{n}, x_{n}\right), \quad \forall n \geq 0 \text {. }
$$


It follows from (2.1), (2.3), (G5) and Proposition 1.4 that

$$
\begin{aligned}
& G_{1}\left(g x_{n}, g x_{n+1}, g x_{n+1}\right) \\
& =G_{1}\left(F\left(x_{n-1}, y_{n-1}\right), F\left(x_{n}, y_{n}\right), F\left(x_{n}, y_{n}\right)\right) \\
& \leq a_{1} G_{2}\left(g x_{n-1}, g x_{n}, g x_{n}\right)+a_{2} G_{2}\left(g y_{n-1}, g y_{n}, g y_{n}\right) \\
& +a_{3} G_{2}\left(F\left(x_{n-1}, y_{n-1}\right), g x_{n-1}, g x_{n-1}\right) \\
& +a_{4} G_{2}\left(F\left(x_{n}, y_{n}\right), g x_{n}, g x_{n}\right)+a_{5} G_{2}\left(F\left(x_{n}, y_{n}\right), g x_{n}, g x_{n}\right) \\
& +a_{6} G_{2}\left(F\left(x_{n-1}, y_{n-1}\right), g x_{n}, g x_{n}\right) \\
& +a_{7} G_{2}\left(F\left(x_{n}, y_{n}\right), g x_{n}, g x_{n-1}\right)+a_{8} G_{2}\left(F\left(x_{n}, y_{n}\right), g x_{n-1}, g x_{n}\right) \\
& +a_{9} G_{2}\left(F\left(x_{n-1}, y_{n-1}\right), g x_{n-1}, g x_{n}\right)+a_{10} G_{2}\left(F\left(x_{n}, y_{n}\right), g x_{n}, g x_{n}\right) \\
& +a_{11} G_{2}\left(F\left(x_{n}, y_{n}\right), g x_{n}, g x_{n-1}\right)+a_{12} G_{2}\left(F\left(x_{n-1}, y_{n-1}\right), F\left(x_{n}, y_{n}\right), g x_{n}\right) \\
& +a_{13} G_{2}\left(F\left(x_{n}, y_{n}\right), F\left(x_{n}, y_{n}\right), g x_{n-1}\right)+a_{14} G_{2}\left(F\left(x_{n}, y_{n}\right), F\left(x_{n-1}, y_{n-1}\right), g x_{n}\right) \\
& =a_{1} G_{2}\left(g x_{n-1}, g x_{n}, g x_{n}\right)+a_{2} G_{2}\left(g y_{n-1}, g y_{n}, g y_{n}\right)+a_{3} G_{2}\left(g x_{n}, g x_{n-1}, g x_{n-1}\right) \\
& +a_{4} G_{2}\left(g x_{n+1}, g x_{n}, g x_{n}\right)+a_{5} G_{2}\left(g x_{n+1}, g x_{n}, g x_{n}\right)+a_{6} G_{2}\left(g x_{n}, g x_{n}, g x_{n}\right) \\
& +a_{7} G_{2}\left(g x_{n+1}, g x_{n}, g x_{n-1}\right)+a_{8} G_{2}\left(g x_{n+1}, g x_{n-1}, g x_{n}\right)+a_{9} G_{2}\left(g x_{n}, g x_{n-1}, g x_{n}\right) \\
& +a_{10} G_{2}\left(g x_{n+1}, g x_{n}, g x_{n}\right)+a_{11} G_{2}\left(g x_{n+1}, g x_{n}, g x_{n-1}\right)+a_{12} G_{2}\left(g x_{n}, g x_{n+1}, g x_{n}\right) \\
& +a_{13} G_{2}\left(g x_{n+1}, g x_{n+1}, g x_{n-1}\right)+a_{14} G_{2}\left(g x_{n+1}, g x_{n}, g x_{n}\right) \\
& =\left(a_{1}+a_{9}\right) G_{2}\left(g x_{n-1}, g x_{n}, g x_{n}\right)+a_{2} G_{2}\left(g y_{n-1}, g y_{n}, g y_{n}\right)+a_{3} G_{2}\left(g x_{n}, g x_{n-1}, g x_{n-1}\right) \\
& +\left(a_{4}+a_{5}+a_{10}+a_{12}+a_{14}\right) G_{2}\left(g x_{n+1}, g x_{n}, g x_{n}\right) \\
& +\left(a_{7}+a_{8}+a_{11}\right) G_{2}\left(g x_{n-1}, g x_{n}, g x_{n+1}\right) \\
& +a_{13} G_{2}\left(g x_{n+1}, g x_{n+1}, g x_{n-1}\right) \\
& \leq\left(a_{1}+a_{9}\right) G_{2}\left(g x_{n-1}, g x_{n}, g x_{n}\right)+a_{2} G_{2}\left(g y_{n-1}, g y_{n}, g y_{n}\right)+2 a_{3} G_{2}\left(g x_{n-1}, g x_{n}, g x_{n}\right) \\
& +2\left(a_{4}+a_{5}+a_{10}+a_{12}+a_{14}\right) G_{2}\left(g x_{n}, g x_{n+1}, g x_{n+1}\right) \\
& +\left(a_{7}+a_{8}+a_{11}\right)\left[G_{2}\left(g x_{n-1}, g x_{n}, g x_{n}\right)+G_{2}\left(g x_{n}, g x_{n}, g x_{n+1}\right)\right] \\
& +a_{13}\left[G_{2}\left(g x_{n-1}, g x_{n}, g x_{n}\right)+G_{2}\left(g x_{n}, g x_{n+1}, g x_{n+1}\right)\right] \\
& \leq\left(a_{1}+2 a_{3}+a_{7}+a_{8}+a_{9}+a_{11}+a_{13}\right) G_{2}\left(g x_{n-1}, g x_{n}, g x_{n}\right)+a_{2} G_{2}\left(g y_{n-1}, g y_{n}, g y_{n}\right) \\
& +\left[2\left(a_{4}+a_{5}+a_{7}+a_{8}+a_{10}+a_{11}+a_{12}+a_{14}\right)+a_{13}\right] G_{1}\left(g x_{n}, g x_{n+1}, g x_{n+1}\right),
\end{aligned}
$$

which implies that

$$
\begin{aligned}
& G_{1}\left(g x_{n}, g x_{n+1}, g x_{n+1}\right) \\
& \quad \leq \frac{\left(a_{1}+2 a_{3}+a_{7}+a_{8}+a_{9}+a_{11}+a_{13}\right) G_{2}\left(g x_{n-1}, g x_{n}, g x_{n}\right)+a_{2} G_{2}\left(g y_{n-1}, g y_{n}, g y_{n}\right)}{1-2\left(a_{4}+a_{5}+a_{7}+a_{8}+a_{10}+a_{11}+a_{12}+a_{14}\right)-a_{13}} .
\end{aligned}
$$


Similarly, we can prove that

$$
\begin{aligned}
& G_{1}\left(g y_{n}, g y_{n+1}, g y_{n+1}\right) \\
& \quad \leq \frac{\left(a_{1}+2 a_{3}+a_{7}+a_{8}+a_{9}+a_{11}+a_{13}\right) G_{2}\left(g y_{n-1}, g y_{n}, g y_{n}\right)+a_{2} G_{2}\left(g x_{n-1}, g x_{n}, g x_{n}\right)}{1-2\left(a_{4}+a_{5}+a_{7}+a_{8}+a_{10}+a_{11}+a_{12}+a_{14}\right)-a_{13}} .
\end{aligned}
$$

By combining (2.4) and (2.5), we obtain

$$
\begin{aligned}
& G_{1}\left(g x_{n}, g x_{n+1}, g x_{n+1}\right)+G_{1}\left(g y_{n}, g y_{n+1}, g y_{n+1}\right) \\
& \quad \leq \lambda\left[G_{2}\left(g x_{n-1}, g x_{n}, g x_{n}\right)+G_{2}\left(g y_{n-1}, g y_{n}, g y_{n}\right)\right],
\end{aligned}
$$

where $\lambda=\frac{a_{1}+a_{2}+2 a_{3}+a_{7}+a_{8}+a_{9}+a_{11}+a_{13}}{1-2\left(a_{4}+a_{5}+a_{7}+a_{8}+a_{10}+a_{11}+a_{12}+a_{14}\right)-a_{13}}$. Obviously, $0 \leq \lambda<1$.

Repeating the above inequality (2.6) $n$ times, we get

$$
\begin{aligned}
G_{1} & \left(g x_{n}, g x_{n+1}, g x_{n+1}\right)+G_{1}\left(g y_{n}, g y_{n+1}, g y_{n+1}\right) \\
& \leq \lambda\left[G_{2}\left(g x_{n-1}, g x_{n}, g x_{n}\right)+G_{2}\left(g y_{n-1}, g y_{n}, g y_{n}\right)\right] \\
& \leq \lambda\left[G_{1}\left(g x_{n-1}, g x_{n}, g x_{n}\right)+G_{1}\left(g y_{n-1}, g y_{n}, g y_{n}\right)\right] \\
& \leq \lambda^{2}\left[G_{2}\left(g x_{n-2}, g x_{n-1}, g x_{n-1}\right)+G_{2}\left(g y_{n-2}, g y_{n-1}, g y_{n-1}\right)\right] \\
& \leq \lambda^{2}\left[G_{1}\left(g x_{n-2}, g x_{n-1}, g x_{n-1}\right)+G_{1}\left(g y_{n-2}, g y_{n-1}, g y_{n-1}\right)\right] \\
& \leq \cdots \leq \lambda^{n}\left[G_{2}\left(g x_{0}, g x_{1}, g x_{1}\right)+G_{2}\left(g y_{0}, g y_{1}, g y_{1}\right)\right] .
\end{aligned}
$$

Next, we shall prove that $\left\{g x_{n}\right\}$ and $\left\{g y_{n}\right\}$ are G-Cauchy sequences in $g(X)$.

In fact, for each $n, m \in \mathbb{N}, m>n$, from (G5) and (2.7), we have

$$
\begin{aligned}
& G_{1}\left(g x_{n}, g x_{m}, g x_{m}\right)+G_{1}\left(g y_{n}, g y_{m}, g y_{m}\right) \\
& \leq G_{1}\left(g x_{n}, g x_{n+1}, g x_{n+1}\right)+G_{1}\left(g x_{n+1}, g x_{n+2}, g x_{n+2}\right) \\
&+G_{1}\left(g y_{n}, g y_{n+1}, g y_{n+1}\right)+G_{1}\left(g y_{n+1}, g y_{n+2}, g y_{n+2}\right) \\
&+\cdots+G_{1}\left(g x_{m-2}, g x_{m-1}, g x_{m-1}\right)+G_{1}\left(g x_{m-1}, g x_{m}, g x_{m}\right) \\
&+G_{1}\left(g y_{m-2}, g y_{m-1}, g y_{m-1}\right)+G_{1}\left(g y_{m-1}, g y_{m}, g y_{m}\right) \\
& \leq {\left[\lambda^{n}+\lambda^{n+1}+\cdots+\lambda^{m-1}\right]\left[G_{2}\left(g x_{0}, g x_{1}, g x_{1}\right)+G_{2}\left(g y_{0}, g y_{1}, g y_{1}\right)\right] } \\
& \leq \frac{\lambda^{n}}{1-\lambda}\left[G_{2}\left(g x_{0}, g x_{1}, g x_{1}\right)+G_{2}\left(g y_{0}, g y_{1}, g y_{1}\right)\right],
\end{aligned}
$$

which implies that

$$
\lim _{n, m \rightarrow \infty}\left[G_{1}\left(g x_{n}, g x_{m}, g x_{m}\right)+G_{1}\left(g y_{n}, g y_{m}, g y_{m}\right)\right]=0
$$

and so

$$
\lim _{n, m \rightarrow \infty} G_{1}\left(g x_{n}, g x_{m}, g x_{m}\right)=0 \text { and } \lim _{n, m \rightarrow \infty} G_{1}\left(g y_{n}, g y_{m}, g y_{m}\right)=0 .
$$


Hence $\left\{g x_{n}\right\}$ and $\left\{g y_{n}\right\}$ are $G_{1}$-Cauchy sequences in $g(X)$. By $G_{1}$-completeness of $g(X)$, there exist $g x, g y \in g(X)$ such that $\left\{g x_{n}\right\}$ and $\left\{g y_{n}\right\}$ converge to $g x$ and $g y$, respectively.

Now we prove that $F(x, y)=g x$ and $F(y, x)=g y$. In fact, it follows from (G5) and (2.1) that

$$
\begin{aligned}
G_{1}( & (x, y), g x, g x) \\
\leq & G_{1}\left(F(x, y), g x_{n+1}, g x_{n+1}\right)+G_{1}\left(g x_{n+1}, g x, g x\right) \\
= & G_{1}\left(F(x, y), F\left(x_{n}, y_{n}\right), F\left(x_{n}, y_{n}\right)\right)+G_{1}\left(g x_{n+1}, g x, g x\right) \\
\leq & a_{1} G_{2}\left(g x, g x_{n}, g x_{n}\right)+a_{2} G_{2}\left(g y, g y_{n}, g y_{n}\right)+a_{3} G_{2}(F(x, y), g x, g x) \\
& +a_{4} G_{2}\left(F\left(x_{n}, y_{n}\right), g x_{n}, g x_{n}\right)+a_{5} G_{2}\left(F\left(x_{n}, y_{n}\right), g x_{n}, g x_{n}\right)+a_{6} G_{2}\left(F(x, y), g x_{n}, g x_{n}\right) \\
& +a_{7} G_{2}\left(F\left(x_{n}, y_{n}\right), g x_{n}, g x\right)+a_{8} G_{2}\left(F\left(x_{n}, y_{n}\right), g x, g x_{n}\right)+a_{9} G_{2}\left(F(x, y), g x, g x_{n}\right) \\
& +a_{10} G_{2}\left(F\left(x_{n}, y_{n}\right), g x_{n}, g x_{n}\right)+a_{11} G_{2}\left(F\left(x_{n}, y_{n}\right), g x_{n}, g x\right) \\
& +a_{12} G_{2}\left(F(x, y), F\left(x_{n}, y_{n}\right), g x_{n}\right) \\
& +a_{13} G_{2}\left(F\left(x_{n}, y_{n}\right), F\left(x_{n}, y_{n}\right), g x\right)+a_{14} G_{2}\left(F\left(x_{n}, y_{n}\right), F(x, y), g x_{n}\right)+G_{1}\left(g x_{n+1}, g x, g x\right) \\
\leq & a_{1} G_{1}\left(g x, g x_{n}, g x_{n}\right)+a_{2} G_{1}\left(g y, g y_{n}, g y_{n}\right)+a_{3} G_{1}(F(x, y), g x, g x) \\
& +a_{4} G_{1}\left(g x_{n+1}, g x_{n}, g x_{n}\right)+a_{5} G_{1}\left(g x_{n+1}, g x_{n}, g x_{n}\right)+a_{6} G_{1}\left(F(x, y), g x_{n}, g x_{n}\right) \\
& +a_{7} G_{1}\left(g x_{n+1}, g x_{n}, g x\right)+a_{8} G_{1}\left(g x_{n+1}, g x, g x_{n}\right)+a_{9} G_{1}\left(F(x, y), g x, g x_{n}\right) \\
& +a_{10} G_{1}\left(g x_{n+1}, g x_{n}, g x_{n}\right)+a_{11} G_{1}\left(g x_{n+1}, g x_{n}, g x\right)+a_{12} G_{1}\left(F(x, y), g x_{n+1}, g x_{n}\right) \\
& +a_{13} G_{1}\left(g x_{n+1}, g x_{n+1}, g x\right)+a_{14} G_{1}\left(g x_{n+1}, F(x, y), g x_{n}\right)+G G_{1}\left(g x_{n+1}, g x, g x\right) .
\end{aligned}
$$

Letting $n \rightarrow \infty$ in the above inequality, we obtain

$$
G_{1}(F(x, y), g x, g x) \leq\left(a_{3}+a_{6}+a_{9}+a_{12}+a_{14}\right) G_{1}(F(x, y), g x, g x) .
$$

By (2.2) we have that $a_{3}+a_{6}+a_{9}+a_{12}+a_{14}<1$. Hence, it follows from (2.8) that $G_{1}(F(x, y), g x, g x)=0$, and so $F(x, y)=g x$. In the same way, we can show that $F(y, x)=g y$. Hence, $(g x, g y)$ is a coupled point of coincidence of mappings $F$ and $g$.

Next we prove that $g x=g y$. In fact, from (2.1) we have

$$
\begin{aligned}
& G_{1}(g x, g y, g y) \\
&= G_{1}(F(x, y), F(y, x), F(y, x)) \\
& \leq a_{1} G_{2}(g x, g y, g y)+a_{2} G_{2}(g y, g x, g x)+a_{3} G_{2}(F(x, y), g x, g x) \\
&+a_{4} G_{2}(F(y, x), g y, g y)+a_{5} G_{2}(F(y, x), g y, g y)+a_{6} G_{2}(F(x, y), g y, g y) \\
&+a_{7} G_{2}(F(y, x), g y, g x)+a_{8} G_{2}(F(y, x), g x, g y)+a_{9} G_{2}(F(x, y), g x, g y) \\
&+a_{10} G_{2}(F(y, x), g y, g y)+a_{11} G_{2}(F(y, x), g y, g x)+a_{12} G_{2}(F(x, y), F(y, x), g y) \\
&+a_{13} G_{2}(F(y, x), F(y, x), g x)+a_{14} G_{2}(F(y, x), F(x, y), g y) \\
&= a_{1} G_{2}(g x, g y, g y)+a_{2} G_{2}(g y, g x, g x)+a_{3} G_{2}(g x, g x, g x) \\
&+a_{4} G_{2}(g y, g y, g y)+a_{5} G_{2}(g y, g y, g y)+a_{6} G_{2}(g x, g y, g y)
\end{aligned}
$$




$$
\begin{aligned}
& +a_{7} G_{2}(g y, g y, g x)+a_{8} G_{2}(g y, g x, g y)+a_{9} G_{2}(g x, g x, g y) \\
& +a_{10} G_{2}(g y, g y, g y)+a_{11} G_{2}(g y, g y, g x)+a_{12} G_{2}(g x, g y, g y) \\
& +a_{13} G_{2}(g y, g y, g x)+a_{14} G_{2}(g y, g x, g y) \\
= & \left(a_{1}+a_{6}+a_{7}+a_{8}+a_{11}+a_{12}+a_{13}+a_{14}\right) G_{2}(g x, g y, g y) \\
& +\left(a_{2}+a_{9}\right) G_{2}(g y, g x, g x) \\
\leq & \left(a_{1}+a_{6}+a_{7}+a_{8}+a_{11}+a_{12}+a_{13}+a_{14}\right) G_{1}(g x, g y, g y) \\
& +\left(a_{2}+a_{9}\right) G_{1}(g y, g x, g x),
\end{aligned}
$$

which implies that

$$
G_{1}(g x, g y, g y) \leq \frac{a_{2}+a_{9}}{1-\left(a_{1}+a_{6}+a_{7}+a_{8}+a_{11}+a_{12}+a_{13}+a_{14}\right)} G_{1}(g y, g x, g x) .
$$

In a similar way, we can show that

$$
G_{1}(g y, g x, g x) \leq \frac{a_{2}+a_{9}}{1-\left(a_{1}+a_{6}+a_{7}+a_{8}+a_{11}+a_{12}+a_{13}+a_{14}\right)} G_{1}(g x, g y, g y) .
$$

Since $\frac{a_{2}+a_{9}}{1-\left(a_{1}+a_{6}+a_{7}+a_{8}+a_{11}+a_{12}+a_{13}+a_{14}\right)}<1$, from (2.9) and (2.10), we must have $G_{1}(g x, g y, g y)=0$ so that $g x=g y$. Thus, $(g x, g x)$ is a coupled point of coincidence of mappings $F$ and $g$.

Now, we claim that a coupled point of coincidence is unique. Suppose that there is another $x^{*} \in X$ such $\left(g x^{*}, g x^{*}\right)$ is a coupled point of coincidence of mappings $F$ and $g$, then by (2.1) we have

$$
\begin{aligned}
& G_{1}\left(g x, g x^{*}, g x^{*}\right) \\
&=G_{1}\left(F(x, x), F\left(x^{*}, x^{*}\right), F\left(x^{*}, x^{*}\right)\right) \\
& \leq a_{1} G_{2}\left(g x, g x^{*}, g x^{*}\right)+a_{2} G_{2}\left(g x, g x^{*}, g x^{*}\right)+a_{3} G_{2}(F(x, x), g x, g x) \\
&+a_{4} G_{2}\left(F\left(x^{*}, x^{*}\right), g x^{*}, g x^{*}\right)+a_{5} G_{2}\left(F\left(x^{*}, x^{*}\right), g x^{*}, g x^{*}\right)+a_{6} G_{2}\left(F(x, x), g x^{*}, g x^{*}\right) \\
&+a_{7} G_{2}\left(F\left(x^{*}, x^{*}\right), g x^{*}, g x\right)+a_{8} G_{2}\left(F\left(x^{*}, x^{*}\right), g x, g x^{*}\right)+a_{9} G_{2}\left(F(x, x), g x, g x^{*}\right) \\
&+a_{10} G_{2}\left(F\left(x^{*}, x^{*}\right), g x^{*}, g x^{*}\right)+a_{11} G_{2}\left(F\left(x^{*}, x^{*}\right), g x^{*}, g x\right) \\
&+a_{12} G_{2}\left(F(x, x), F\left(x^{*}, x^{*}\right), g x^{*}\right) \\
&+a_{13} G_{2}\left(F\left(x^{*}, x^{*}\right), F\left(x^{*}, x^{*}\right), g x\right)+a_{14} G_{2}\left(F\left(x^{*}, x^{*}\right), F(x, x), g x^{*}\right) \\
&= a_{1} G_{2}\left(g x, g x^{*}, g x^{*}\right)+a_{2} G_{2}\left(g x, g x^{*}, g x^{*}\right)+a_{3} G_{2}(g x, g x, g x) \\
&+a_{4} G_{2}\left(g x^{*}, g x^{*}, g x^{*}\right)+a_{5} G_{2}\left(g x^{*}, g x^{*}, g x^{*}\right)+a_{6} G_{2}\left(g x, g x^{*}, g x^{*}\right) \\
&+a_{7} G_{2}\left(g x^{*}, g x^{*}, g x\right)+a_{8} G_{2}\left(g x^{*}, g x, g x^{*}\right)+a_{9} G_{2}\left(g x, g x, g x^{*}\right) \\
&+a_{10} G_{2}\left(g x^{*}, g x^{*}, g x^{*}\right)+a_{11} G_{2}\left(g x^{*}, g x^{*}, g x\right)+a_{12} G_{2}\left(g x, g x^{*}, g x^{*}\right) \\
&+a_{13} G_{2}\left(g x^{*}, g x^{*}, g x\right)+a_{14} G_{2}\left(g x^{*}, g x, g x^{*}\right) \\
&=\left(a_{1}+a_{2}+a_{6}+a_{7}+a_{8}+a_{11}+a_{12}+a_{13}+a_{14}\right) G_{2}\left(g x, g x^{*}, g x^{*}\right) \\
&+a_{9} G_{2}\left(g x, g x, g x^{*}\right)
\end{aligned}
$$




$$
\begin{aligned}
\leq & \left(a_{1}+a_{2}+a_{6}+a_{7}+a_{8}+a_{11}+a_{12}+a_{13}+a_{14}\right) G_{1}\left(g x, g x^{*}, g x^{*}\right) \\
& +a_{9} G_{1}\left(g x, g x, g x^{*}\right),
\end{aligned}
$$

which implies that

$$
\begin{aligned}
& G_{1}\left(g x, g x^{*}, g x^{*}\right) \\
& \quad \leq \frac{a_{9}}{1-\left(a_{1}+a_{2}+a_{6}+a_{7}+a_{8}+a_{11}+a_{12}+a_{13}+a_{14}\right)} G_{1}\left(g x, g x, g x^{*}\right) .
\end{aligned}
$$

In the same way, we can show that

$$
\begin{aligned}
& G_{1}\left(g x^{*}, g x, g x\right) \\
& \quad \leq \frac{a_{9}}{1-\left(a_{1}+a_{2}+a_{6}+a_{7}+a_{8}+a_{11}+a_{12}+a_{13}+a_{14}\right)} G_{1}\left(g x^{*}, g x^{*}, g x\right) .
\end{aligned}
$$

Since $\frac{a_{9}}{1-\left(a_{1}+a_{2}+a_{6}+a_{7}+a_{8}+a_{11}+a_{12}+a_{13}+a_{14}\right)}<1$, from (2.11) and (2.12), we must have $G_{1}(g x, g x$, $\left.g x^{*}\right)=0$ so that $g x=g x^{*}$. Hence, $(g x, g x)$ is a unique coupled point of coincidence of mappings $F$ and $g$.

Now we show that $F$ and $g$ have a unique common coupled fixed point. For this, let $g x=u$. Then we have $u=g x=F(x, x)$. By $w^{*}$-compatibility of $F$ and $g$, we have

$$
g u=g(g x)=g F(x, x)=F(g x, g x)=F(u, u) .
$$

Thus, $(g u, g u)$ is a coupled point of coincidence of $F$ and $g$. By the uniqueness of a coupled point of coincidence, we have $g u=g x$. Therefore, $u=g u=F(u, u)$.

To prove the uniqueness, let $u^{*} \in X$ with $u^{*} \neq u$ such that

$$
u^{*}=g u^{*}=F\left(u^{*}, u^{*}\right) \text { and } u=g u=F(u, u) \text {. }
$$

By using (2.1), following the same arguments as in the proof of (2.11) and (2.12), we obtain

$$
\begin{aligned}
& G_{1}\left(g u, g u^{*}, g u^{*}\right) \\
& \quad \leq \frac{a_{9}}{1-\left(a_{1}+a_{2}+a_{6}+a_{7}+a_{8}+a_{11}+a_{12}+a_{13}+a_{14}\right)} G_{1}\left(g u, g u, g u^{*}\right)
\end{aligned}
$$

and

$$
\begin{aligned}
& G_{1}\left(g u^{*}, g u, g u\right) \\
& \quad \leq \frac{a_{9}}{1-\left(a_{1}+a_{2}+a_{6}+a_{7}+a_{8}+a_{11}+a_{12}+a_{13}+a_{14}\right)} G_{1}\left(g u^{*}, g u^{*}, g u\right) .
\end{aligned}
$$

Since $\frac{a_{9}}{1-\left(a_{1}+a_{2}+a_{6}+a_{7}+a_{8}+a_{11}+a_{12}+a_{13}+a_{14}\right)}<1$, from (2.13) and (2.14), we must have $G_{1}(g u, g u$, $\left.g u^{*}\right)=0$ so that $u=g u=g u^{*}=u^{*}$. Thus, $F$ and $g$ have a unique common coupled fixed point. This completes the proof of Theorem 2.1 .

Remark 2.3 Theorem 2.2 improves and extends Theorem 2.1 of Abbas et al. [25], the contractive condition defined by (1.1) is replaced by the new contractive condition defined 
by (2.1). Theorem 2.1 also improves and extends Theorem 2.4, Corollaries 2.5-2.8 and Theorem 2.11 of Abbas et al. [22]

Now, we introduce an example to support Theorem 2.2.

Example 2.4 Let $X=[0,1]$, and let two $G$-metrics $G_{1}, G_{2}$ on $X$ be given as

$$
\begin{aligned}
& G_{1}(x, y, z)=|x-y|+|y-z|+|z-x| \text { and } \\
& G_{2}(x, y, z)=\frac{1}{2}[|x-y|+|y-z|+|z-x|]
\end{aligned}
$$

for all $x, y, z \in X$. Define $F: X \times X \rightarrow X$ and $g: X \rightarrow X$ as

$$
F(x, y)=\frac{x+y}{32} \text { and } g x=\frac{x}{2}
$$

for all $z, y \in X$.

Now, for $(x, y),(u, v),(s, t) \in X \times X$, we have

$$
\begin{aligned}
G_{1} & F(x, y), F(u, v), F(s, t)) \\
= & G_{1}\left(\frac{x+y}{32}, \frac{u+v}{32}, \frac{s+t}{32}\right) \\
= & \frac{1}{32}[|x+y-(u+v)|+|u+v-(s+t)|+|s+t-(x+y)|] \\
\leq & \frac{1}{32}[|x-u|+|y-v|+|u-s|+|v-t|+|s-x|+|t-y|] \\
= & \frac{1}{8}\left\{\frac{1}{4}[|x-u|+|y-v|+|u-s|]+\frac{1}{4}[|v-t|+|s-x|+|t-y|]\right\} \\
= & \frac{1}{8} G_{2}(g x, g u, g s)+\frac{1}{8} G_{2}(g y, g v, g t) \\
\leq & \frac{1}{8} G_{2}(g x, g u, g s)+\frac{1}{8} G_{2}(g y, g v, g t)+\frac{1}{112} G(F(x, y), g x, g x) \\
& +\frac{1}{112} G_{2}(F(u, v), g u, g u)+\frac{1}{112} G_{2}(F(s, t), g s, g s)+\frac{1}{16} G_{2}(F(x, y), g u, g s) \\
& +\frac{1}{72} G_{2}(F(u, v), g s, g x)+\frac{1}{72} G_{2}(F(s, t), g x, g u)+\frac{1}{16} G_{2}(F(x, y), g x, g u) \\
& +\frac{1}{112} G_{2}(F(u, v), g u, g s)+\frac{1}{72} G_{2}(F(s, t), g s, g x)+\frac{1}{112} G_{2}(F(x, y), F(u, v), g s) \\
& +\frac{1}{112} G_{2}(F(u, v), F(s, t), g x)+\frac{1}{112} G_{2}(F(s, t), F(x, y), g u) \\
&
\end{aligned}
$$

for all $(x, y),(u, v),(w, z) \in X \times X$. Thus, (2.1) is satisfied with $a_{1}=a_{2}=\frac{1}{8}, a_{3}=a_{4}=a_{5}=$ $a_{10}=a_{12}=a_{13}=a_{14}=\frac{1}{112}, a_{6}=a_{9}=\frac{1}{16}$ and $a_{7}=a_{8}=a_{11}=\frac{1}{72}$, where

$$
a_{1}+a_{2}+a_{6}+a_{9}+2\left(a_{3}+a_{4}+a_{5}+a_{10}+a_{12}+a_{13}+a_{14}\right)+3\left(a_{7}+a_{8}+a_{11}\right)=\frac{23}{48}<1 .
$$

It is obvious that $F$ is $w^{*}$-compatible with $g$. Hence, all the conditions of Theorem 2.2 are satisfied. Moreover, $(0,0)$ is the unique common coupled fixed point of $F$ and $g$. 
In Theorem 2.2, take $\alpha_{1}=a_{1}, \alpha_{2}=a_{2}, \alpha_{3}=a_{6}, \alpha_{4}=a_{3}, \alpha_{5}=a_{10}, \alpha_{6}=a_{13}$ and $a_{4}=a_{5}=$ $a_{7}=a_{8}=a_{9}=a_{11}=a_{12}=a_{14}=0$, to obtain Theorem 2.1 of Abbas et al. [25] as the following corollary.

Corollary 2.5 Let $G_{1}$ and $G_{2}$ be two G-metrics on $X$ such that $G_{2}(x, y, z) \leq G_{1}(x, y, z)$ for all $x, y, z \in X$, and let $F: X \times X \rightarrow X, g: X \rightarrow X$ be two mappings satisfying

$$
\begin{aligned}
G_{1}( & F(x, y), F(u, v), F(s, t)) \\
\quad \leq & \alpha_{1} G_{2}(g x, g u, g s)+\alpha_{2} G_{2}(g y, g v, g t)+\alpha_{3} G_{2}(F(x, y), g u, g s) \\
& \quad+\alpha_{4} G_{2}(F(x, y), g x, g x)+\alpha_{5} G_{2}(F(u, v), g u, g s)+\alpha_{6} G_{2}(F(u, v), F(s, t), g x)
\end{aligned}
$$

for all $(x, y),(u, v),(s, t) \in X \times X$, where $\alpha_{i} \geq 0$, for $i=1,2, \ldots, 6$ and $\alpha_{1}+\alpha_{2}+\alpha_{3}+2\left(\alpha_{4}+\right.$ $\left.\alpha_{5}+\alpha_{6}\right)<1$. If $F(X \times X) \subset g(X)$ and $g(X)$ is a $G_{1}$-complete subspace of $X$, and $F$ and $g$ are $w^{*}$-compatible, then $F$ and $g$ have a unique common coupled fixed point.

In Theorem 2.2, take $s=u$ and $t=v$ to obtain the following corollary, which extends and generalizes the corresponding results of $[22,23,25]$.

Corollary 2.6 Let $G_{1}$ and $G_{2}$ be two $G$-metrics on $X$ such that $G_{2}(x, y, z) \leq G_{1}(x, y, z)$ for all $x, y, z \in X$, and let $F: X \times X \rightarrow X, g: X \rightarrow X$ be two mappings satisfying

$$
\begin{aligned}
G_{1}( & (x, y), F(u, v), F(u, v)) \\
\leq & a_{1} G_{2}(g x, g u, g u)+a_{2} G_{2}(g y, g v, g v)+a_{3} G_{2}(F(x, y), g x, g x) \\
& +a_{4} G_{2}(F(u, v), g u, g u)+a_{5} G_{2}(F(u, v), g u, g u)+a_{6} G_{2}(F(x, y), g u, g u) \\
& +a_{7} G_{2}(F(u, v), g u, g x)+a_{8} G_{2}(F(u, v), g x, g u)+a_{9} G_{2}(F(x, y), g x, g u) \\
& +a_{10} G_{2}(F(u, v), g u, g u)+a_{11} G_{2}(F(u, v), g u, g x)+a_{12} G_{2}(F(x, y), F(u, v), g u) \\
& +a_{13} G_{2}(F(u, v), F(u, v), g x)+a_{14} G_{2}(F(u, v), F(x, y), g u)
\end{aligned}
$$

for all $(x, y),(u, v) \in X \times X$, where $a_{i} \geq 0$, for $i=1,2, \ldots, 14$ and

$$
a_{1}+a_{2}+a_{6}+a_{9}+2\left(a_{3}+a_{4}+a_{5}+a_{10}+a_{12}+a_{13}+a_{14}\right)+3\left(a_{7}+a_{8}+a_{11}\right)<1 .
$$

If $F(X \times X) \subset g(X)$ and $g(X)$ is a $G_{1}$-complete subspace of $X$, and $F$ and $g$ are $w^{*}$-compatible, then $F$ and $g$ have a unique common coupled fixed point.

If we take $\alpha=a_{1}, \beta=a_{2}, \gamma=a_{6}$ and $a_{3}=a_{4}=a_{5}=a_{7}=a_{8}=a_{9}=a_{10}=a_{11}=a_{12}=a_{13}=$ $a_{14}=0$ in Theorem 2.2, then the following corollary, which extends and generalizes the comparable results of $[22,23]$, is obtained.

Corollary 2.7 Let $G_{1}$ and $G_{2}$ be two $G$-metrics on $X$ such that $G_{2}(x, y, z) \leq G_{1}(x, y, z)$ for all $x, y, z \in X$, and let $F: X \times X \rightarrow X, g: X \rightarrow X$ be two mappings satisfying

$$
\begin{aligned}
& G_{1}(F(x, y), F(u, v), F(s, t)) \\
& \quad \leq \alpha G_{2}(g x, g u, g s)+\beta G_{2}(g y, g v, g t)+\gamma G_{2}(F(x, y), g u, g s)
\end{aligned}
$$


for all $(x, y),(u, v),(s, t) \in X \times X$, where $\alpha, \beta, \gamma \geq 0$ and $\alpha+\beta+\gamma<1$.If $F(X \times X) \subset g(X)$ and $g(X)$ is a $G_{1}$-complete subspace of $X$, and $F$ and $g$ are $w^{*}$-compatible, then $F$ and $g$ have a unique common coupled fixed point.

If we take $\alpha=a_{1}, \beta=a_{2}, \gamma=a_{6}, \delta=a_{9}$ and $a_{3}=a_{4}=a_{5}=a_{7}=a_{8}=a_{10}=a_{11}=a_{12}=a_{13}=$ $a_{14}=0$ in Theorem 2.2, then the following corollary is obtained.

Corollary 2.8 Let $G_{1}$ and $G_{2}$ be two G-metrics on $X$ such that $G_{2}(x, y, z) \leq G_{1}(x, y, z)$ for all $x, y, z \in X$, and let $F: X \times X \rightarrow X, g: X \rightarrow X$ be two mappings satisfying

$$
\begin{aligned}
G_{1}(F(x, y), F(u, v), F(s, t)) \leq & \alpha G_{2}(g x, g u, g s)+\beta G_{2}(g y, g v, g t) \\
& +\gamma G_{2}(F(x, y), g u, g s)+\delta G_{2}(F(x, y), g x, g u)
\end{aligned}
$$

for all $(x, y),(u, v),(s, t) \in X \times X$, where $\alpha, \beta, \gamma, \delta \geq 0$ and $\alpha+\beta+\gamma+\delta<1$. IfF $(X \times X) \subset g(X)$ and $g(X)$ is a $G_{1}$-complete subspace of $X$, and $F$ and $g$ are $w^{*}$-compatible, then $F$ and $g$ have a unique common coupled fixed point.

If we take $\alpha_{1}=a_{3}, \alpha_{2}=a_{4}, \alpha_{3}=a_{5}, \alpha_{4}=a_{10}, \alpha_{5}=a_{12}, \alpha_{6}=a_{13}, \alpha_{7}=a_{14}$ and $a_{1}=a_{2}=a_{6}=$ $a_{7}=a_{8}=a_{9}=a_{11}=0$ in Theorem 2.2, then the following corollary is obtained.

Corollary 2.9 Let $G_{1}$ and $G_{2}$ be two G-metrics on $X$ such that $G_{2}(x, y, z) \leq G_{1}(x, y, z)$ for all $x, y, z \in X$, and let $F: X \times X \rightarrow X, g: X \rightarrow X$ be two mappings satisfying

$$
\begin{aligned}
G_{1}( & F(x, y), F(u, v), F(s, t)) \\
\leq & \alpha_{1} G_{2}(F(x, y), g x, g x)+\alpha_{2} G_{2}(F(u, v), g u, g u)+\alpha_{3} G_{2}(F(s, t), g s, g s) \\
& +\alpha_{4} G_{2}(F(u, v), g u, g s)+\alpha_{5} G_{2}(F(x, y), F(u, v), g s) \\
& +\alpha_{6} G_{2}(F(u, v), F(s, t), g x)+\alpha_{7} G_{2}(F(s, t), F(x, y), g u)
\end{aligned}
$$

for all $(x, y),(u, v),(s, t) \in X \times X$, where $\alpha_{i} \geq 0$, for $i=1,2, \ldots, 7$ and

$$
\alpha_{1}+\alpha_{2}+\alpha_{3}+\alpha_{4}+\alpha_{5}+\alpha_{6}+a_{7}<\frac{1}{2} .
$$

If $F(X \times X) \subset g(X)$ and $g(X)$ is a $G_{1}$-complete subspace of $X$, and $F$ and $g$ are w"-compatible, then $F$ and $g$ have a unique common coupled fixed point.

If we take $\alpha=a_{7}, \beta=a_{8}, \gamma=a_{11}$ and $a_{1}=a_{2}=a_{3}=a_{4}=a_{5}=a_{6}=a_{9}=a_{10}=a_{12}=a_{13}=$ $a_{14}=0$ in Theorem 2.2, then the following corollary is obtained.

Corollary 2.10 Let $G_{1}$ and $G_{2}$ be two $G$-metrics on $X$ such that $G_{2}(x, y, z) \leq G_{1}(x, y, z)$ for all $x, y, z \in X$, and let $F: X \times X \rightarrow X, g: X \rightarrow X$ be two mappings satisfying

$$
\begin{aligned}
& G_{1}(F(x, y), F(u, v), F(s, t)) \\
& \quad \leq \alpha G_{2}(F(u, v), g s, g x)+\beta G_{2}(F(s, t), g x, g u)+\gamma G_{2}(F(s, t), g s, g x)
\end{aligned}
$$


for all $(x, y),(u, v),(s, t) \in X \times X$, where $\alpha, \beta, \gamma \geq 0$ and $\alpha+\beta+\gamma<\frac{1}{3}$. If $F(X \times X) \subset g(X)$ and $g(X)$ is a $G_{1}$-complete subspace of $X$, and $F$ and $g$ are $w^{*}$-compatible, then $F$ and $g$ have a unique common coupled fixed point.

Theorem 2.11 Let $G_{1}$ and $G_{2}$ be two G-metrics on $X$ such that $G_{2}(x, y, z) \leq G_{1}(x, y, z)$ for all $x, y, z \in X$, and let $F: X \times X \rightarrow X, g: X \rightarrow X$ be two mappings satisfying

$$
\begin{aligned}
& G_{1}(F(x, y), F(u, v), F(s, t)) \\
& \quad \leq k \max \left\{\begin{array}{c}
G_{2}(g x, g u, g s), G_{2}(g y, g v, g t), G_{2}(F(x, y), g u, g s), \\
G_{2}(F(x, y), g x, g u), \frac{1}{2} G_{2}\left((F(x, y), g x, g x), \frac{1}{2} G_{2}(F(u, v), g u, g u),\right. \\
\frac{1}{2} G_{2}(F(s, t), g s, g s), \frac{1}{2} G_{2}(F(u, v), g u, g s), \\
\frac{1}{2} G_{2}(F(x, y), F(u, v), g s), \frac{1}{2} G_{2}(F(s, t), F(x, y), g u)
\end{array}\right\}
\end{aligned}
$$

for all $(x, y),(u, v),(s, t) \in X \times X$, where $0 \leq k<1$. If $F(X \times X) \subset g(X)$ and $g(X)$ is a $G_{1}$ complete subspace of $X$, and $F$ and $g$ are $w^{\prime \prime}$-compatible, then $F$ and $g$ have a unique common coupled fixed point.

Proof Let $x_{0}, y_{0} \in X$. We choose $x_{1}, y_{1} \in X$ such that $g x_{1}=F\left(x_{0}, y_{0}\right)$ and $g y_{1}=F\left(y_{0}, x_{0}\right)$, this can be done in view of $F(X \times X) \subset g(X)$. Similarly, we can choose $x_{2}, y_{2} \in X$ such that $g x_{2}=F\left(x_{1}, y_{1}\right)$ and $g y_{2}=F\left(y_{1}, x_{1}\right)$. Continuing this process, we construct two sequences $\left\{x_{n}\right\}$ and $\left\{y_{n}\right\}$ in $X$ such that $g x_{n+1}=F\left(x_{n}, y_{n}\right)$ and $g y_{n+1}=F\left(y_{n}, x_{n}\right)$.

By using (2.21) and Proposition 1.4, we obtain

$$
\begin{aligned}
& G_{1}\left(g x_{n}, g x_{n+1}, g x_{n+1}\right) \\
& =G_{1}\left(F\left(x_{n-1}, y_{n-1}\right), F\left(x_{n}, y_{n}\right), F\left(x_{n}, y_{n}\right)\right) \\
& \leq k \max \left\{\begin{array}{c}
G_{2}\left(g x_{n-1}, g x_{n}, g x_{n}\right), G_{2}\left(g y_{n-1}, g y_{n}, g y_{n}\right), \\
G_{2}\left(F\left(x_{n-1}, y_{n-1}\right), g x_{n}, g x_{n}\right), G_{2}\left(F\left(x_{n-1}, y_{n-1}\right), g x_{n-1}, g x_{n}\right), \\
\frac{1}{2} G_{2}\left(F\left(x_{n-1}, y_{n-1}\right), g x_{n-1}, g x_{n-1}\right), \frac{1}{2} G_{2}\left(F\left(x_{n}, y_{n}\right), g x_{n}, g x_{n}\right), \\
\frac{1}{2} G_{2}\left(F\left(x_{n}, y_{n}\right), g x_{n}, g x_{n}\right), \frac{1}{2} G_{2}\left(F\left(x_{n}, y_{n}\right), g x_{n}, g x_{n}\right), \\
\frac{1}{2} G_{2}\left(F\left(x_{n-1}, y_{n-1}\right), F\left(x_{n}, y_{n}\right), g x_{n}\right), \frac{1}{2} G_{2}\left(F\left(x_{n}, y_{n}\right), F\left(x_{n-1}, y_{n-1}\right), g x_{n}\right)
\end{array}\right\} \\
& =k \max \left\{\begin{array}{c}
G_{2}\left(g x_{n-1}, g x_{n}, g x_{n}\right), G_{2}\left(g y_{n-1}, g y_{n}, g y_{n}\right), \\
G_{2}\left(g x_{n}, g x_{n}, g x_{n}\right), G_{2}\left(g x_{n}, g x_{n-1}, g x_{n}\right), \\
\frac{1}{2} G_{2}\left(g x_{n}, g x_{n-1}, g x_{n-1}\right), \frac{1}{2} G_{2}\left(g x_{n+1}, g x_{n}, g x_{n}\right), 1 \\
\frac{1}{2} G_{2}\left(g x_{n}, g x_{n+1}, g x_{n}\right), \frac{1}{2} G_{2}\left(g x_{n+1}, g x_{n}, g x_{n}\right)
\end{array}\right\} \\
& =k \max \left\{\begin{array}{c}
G_{2}\left(g x_{n-1}, g x_{n}, g x_{n}\right), G_{2}\left(g y_{n-1}, g y_{n}, g y_{n}\right), \\
\frac{1}{2} G_{2}\left(g x_{n}, g x_{n-1}, g x_{n-1}\right), \frac{1}{2} G_{2}\left(g x_{n+1}, g x_{n}, g x_{n}\right)
\end{array}\right\} \\
& =k \max \left\{\begin{array}{c}
G_{2}\left(g x_{n-1}, g x_{n}, g x_{n}\right), G_{2}\left(g y_{n-1}, g y_{n}, g y_{n}\right), \\
G_{2}\left(g x_{n-1}, g x_{n}, g x_{n}\right), G_{2}\left(g x_{n}, g x_{n+1}, g x_{n+1}\right)
\end{array}\right\} \\
& \leq k \max \left\{\begin{array}{c}
\left.G_{2}\left(g x_{n-1}, g x_{n}, g x_{n}\right), G_{2}\left(g y_{n-1}, g y_{n}, g y_{n}\right), G_{2}\left(g x_{n}, g x_{n+1}, g x_{n+1}\right)\right\} \\
\left.G_{1}\left(g x_{n-1}, g x_{n}, g x_{n}\right), G_{1}\left(g y_{n-1}, g y_{n}, g y_{n}\right), G_{1}\left(g x_{n}, g x_{n+1}, g x_{n+1}\right)\right\} .
\end{array}\right.
\end{aligned}
$$


If

$$
\begin{aligned}
& \max \left\{G_{1}\left(g x_{n-1}, g x_{n}, g x_{n}\right), G_{1}\left(g y_{n-1}, g y_{n}, g y_{n}\right), G_{1}\left(g x_{n}, g x_{n+1}, g x_{n+1}\right)\right\} \\
& =G_{1}\left(g x_{n}, g x_{n+1}, g x_{n+1}\right),
\end{aligned}
$$

then inequality (2.22) becomes

$$
G_{1}\left(g x_{n}, g x_{n+1}, g x_{n+1}\right) \leq k G_{1}\left(g x_{n}, g x_{n+1}, g x_{n+1}\right),
$$

which is a contradiction. So that

$$
\begin{aligned}
& \max \left\{G_{1}\left(g x_{n-1}, g x_{n}, g x_{n}\right), G_{1}\left(g y_{n-1}, g y_{n}, g y_{n}\right), G_{1}\left(g x_{n}, g x_{n+1}, g x_{n+1}\right)\right\} \\
& \quad=\max \left\{G_{1}\left(g x_{n-1}, g x_{n}, g x_{n}\right), G_{1}\left(g y_{n-1}, g y_{n}, g y_{n}\right)\right\} .
\end{aligned}
$$

This implies that

$$
G_{1}\left(g x_{n}, g x_{n+1}, g x_{n+1}\right) \leq k \max \left\{G_{1}\left(g x_{n-1}, g x_{n}, g x_{n}\right), G_{1}\left(g y_{n-1}, g y_{n}, g y_{n}\right)\right\} \text {. }
$$

In a similar way, we obtain

$$
G_{1}\left(g y_{n}, g y_{n+1}, g y_{n+1}\right) \leq k \max \left\{G_{1}\left(g y_{n-1}, g y_{n}, g y_{n}\right), G_{1}\left(g x_{n-1}, g x_{n}, g x_{n}\right)\right\} .
$$

Repeating inequalities (2.23) and (2.24), we obtain

$$
\begin{aligned}
G_{1}\left(g x_{n}, g x_{n+1}, g x_{n+1}\right) & \leq k \max \left\{G_{1}\left(g x_{n-1}, g x_{n}, g x_{n}\right), G_{1}\left(g y_{n-1}, g y_{n}, g y_{n}\right)\right\} \\
& \leq k^{2} \max \left\{G_{1}\left(g x_{n-2}, g x_{n-1}, g x_{n-1}\right), G_{1}\left(g y_{n-2}, g y_{n-1}, g y_{n-1}\right)\right\} \\
& \leq k^{3} \max \left\{G_{1}\left(g x_{n-3}, g x_{n-2}, g x_{n-2}\right), G_{1}\left(g y_{n-3}, g y_{n-2}, g y_{n-2}\right)\right\} \\
& \leq \cdots \\
& \leq k^{n} \max \left\{G_{1}\left(g x_{0}, g x_{1}, g x_{1}\right), G_{1}\left(g y_{0}, g y_{1}, g y_{1}\right)\right\}
\end{aligned}
$$

and

$$
\begin{aligned}
G_{1}\left(g y_{n}, g y_{n+1}, g y_{n+1}\right) & \leq k \max \left\{G_{1}\left(g y_{n-1}, g y_{n}, g y_{n}\right), G_{1}\left(g x_{n-1}, g x_{n}, g x_{n}\right)\right\} \\
& \leq k^{2} \max \left\{G_{1}\left(g y_{n-2}, g y_{n-1}, g y_{n-1}\right), G_{1}\left(g x_{n-2}, g x_{n-1}, g x_{n-1}\right)\right\} \\
& \leq k^{3} \max \left\{G_{1}\left(g y_{n-3}, g y_{n-2}, g y_{n-2}\right), G_{1}\left(g x_{n-3}, g x_{n-2}, g x_{n-2}\right)\right\} \\
& \leq \cdots \\
& \leq k^{n} \max \left\{G_{1}\left(g y_{0}, g y_{1}, g y_{1}\right), G_{1}\left(g x_{0}, g x_{1}, g x_{1}\right)\right\} .
\end{aligned}
$$

By virtue of inequalities (2.25) and (2.26), for each $m, n \in \mathbb{N}, m>n$, repeated use (G5) of a G-metric gives

$$
\begin{aligned}
G_{1}\left(g x_{n}, g x_{m}, g x_{m}\right) \leq & G_{1}\left(g x_{n}, g x_{n+1}, g x_{n+1}\right)+G_{1}\left(g x_{n+1}, g x_{n+2}, g x_{n+2}\right) \\
& +\cdots+G_{1}\left(g x_{m-2}, g x_{m-1}, g x_{m-1}\right)+G_{1}\left(g x_{m-1}, g x_{m}, g x_{m}\right)
\end{aligned}
$$




$$
\begin{aligned}
& \leq\left(k^{n}+k^{n+1}+\cdots+k^{m-1}\right) \max \left\{G_{1}\left(g x_{0}, g x_{1}, g x_{1}\right), G_{1}\left(g y_{0}, g y_{1}, g y_{1}\right)\right\} \\
& \leq \frac{k^{n}}{1-k} \max \left\{G_{1}\left(g x_{0}, g x_{1}, g x_{1}\right), G_{1}\left(g y_{0}, g y_{1}, g y_{1}\right)\right\}
\end{aligned}
$$

and

$$
\begin{aligned}
G_{1}\left(g y_{n}, g y_{m}, g y_{m}\right) \leq & G_{1}\left(g y_{n}, g y_{n+1}, g y_{n+1}\right)+G_{1}\left(g y_{n+1}, g y_{n+2}, g y_{n+2}\right) \\
& +\cdots+G_{1}\left(g y_{m-2}, g y_{m-1}, g y_{m-1}\right)+G_{1}\left(g y_{m-1}, g y_{m}, g y_{m}\right) \\
\leq & \left(k^{n}+k^{n+1}+\cdots+k^{m-1}\right) \max \left\{G_{1}\left(g x_{0}, g x_{1}, g x_{1}\right), G_{1}\left(g y_{0}, g y_{1}, g y_{1}\right)\right\} \\
\leq & \frac{k^{n}}{1-k} \max \left\{G_{1}\left(g x_{0}, g x_{1}, g x_{1}\right), G_{1}\left(g y_{0}, g y_{1}, g y_{1}\right)\right\},
\end{aligned}
$$

which implies that

$$
\lim _{n, m \rightarrow \infty} G_{1}\left(g x_{n}, g x_{m}, g x_{m}\right)=0 \text { and } \lim _{n, m \rightarrow \infty} G_{1}\left(g y_{n}, g y_{m}, g y_{m}\right)=0
$$

Hence $\left\{g x_{n}\right\}$ and $\left\{g y_{n}\right\}$ are $G_{1}$-Cauchy sequences in $g(X)$. By $G_{1}$-completeness of $g(X)$, there exist $g x, g y \in g(X)$ such that $\left\{g x_{n}\right\}$ and $\left\{g y_{n}\right\}$ converge to $g x$ and $g y$, respectively.

Now, we prove that $F(x, y)=g x$ and $F(y, x)=g y$. For this, using (G5) and (2.21), we have

$$
\begin{aligned}
& G_{1}(F(x, y), g x, g x) \\
& \leq G_{1}\left(F(x, y), g x_{n+1}, g x_{n+1}\right)+G_{1}\left(g x_{n+1}, g x, g x\right) \\
& =G_{1}\left(F(x, y), F\left(x_{n}, y_{n}\right), F\left(x_{n}, y_{n}\right)\right)+G_{1}\left(g x_{n+1}, g x, g x\right) \\
& \leq k \max \left\{\begin{array}{c}
G_{2}\left(g x, g x_{n}, g x_{n}\right), G_{2}\left(g y, g y_{n}, g y_{n}\right), \\
G_{2}\left(F(x, y), g x_{n}, g x_{n}\right), G_{2}\left(F(x, y), g x, g x_{n}\right), \\
\frac{1}{2} G_{2}(F(x, y), g x, g x), \frac{1}{2} G_{2}\left(F\left(x_{n}, y_{n}\right), g x_{n}, g x_{n}\right), \\
\frac{1}{2} G_{2}\left(F\left(x_{n}, y_{n}\right), g x_{n}, g x_{n}\right), \frac{1}{2} G_{2}\left(F\left(x_{n}, y_{n}\right), g x_{n}, g x_{n}\right), \\
\frac{1}{2} G_{2}\left(F(x, y), F\left(x_{n}, y_{n}\right), g x_{n}\right), \frac{1}{2} G_{2}\left(F\left(x_{n}, y_{n}\right), F(x, y), g x_{n}\right)
\end{array}\right\} \\
& +G_{1}\left(g x_{n+1}, g x, g x\right) \\
& =k \max \left\{\begin{array}{c}
G_{2}\left(g x, g x_{n}, g x_{n}\right), G_{2}\left(g y, g y_{n}, g y_{n}\right), \\
G_{2}\left(F(x, y), g x_{n}, g x_{n}\right), G_{2}\left(F(x, y), g x, g x_{n}\right), \\
\frac{1}{2} G_{2}(F(x, y), g x, g x), \frac{1}{2} G_{2}\left(g x_{n+1}, g x_{n}, g x_{n}\right), \\
\frac{1}{2} G_{2}\left(g x_{n+1}, g x_{n}, g x_{n}\right), \frac{1}{2} G_{2}\left(g x_{n+1}, g x_{n}, g x_{n}\right), \\
\frac{1}{2} G_{2}\left(F(x, y), g x_{n+1}, g x_{n}\right), \frac{1}{2} G_{2}\left(g x_{n+1}, F(x, y), g x_{n}\right)
\end{array}\right\} \\
& +G_{1}\left(g x_{n+1}, g x, g x\right) \\
& =k \max \left\{\begin{array}{c}
G_{2}\left(g x, g x_{n}, g x_{n}\right), G_{2}\left(g y, g y_{n}, g y_{n}\right), \\
G_{2}\left(F(x, y), g x_{n}, g x_{n}\right), G_{2}\left(F(x, y), g x, g x_{n}\right), \\
\frac{1}{2} G_{2}(F(x, y), g x, g x), \frac{1}{2} G_{2}\left(g x_{n+1}, g x_{n}, g x_{n}\right), \\
\frac{1}{2} G_{2}\left(F(x, y), g x_{n+1}, g x_{n}\right), \frac{1}{2} G_{2}\left(g x_{n+1}, F(x, y), g x_{n}\right)
\end{array}\right\} \\
& +G_{1}\left(g x_{n+1}, g x, g x\right) \text {. }
\end{aligned}
$$


On taking the limit as $n \rightarrow \infty$, we obtain that

$$
G_{1}(F(x, y), g x, g x) \leq k G_{2}(F(x, y), g x, g x) \leq k G_{1}(F(x, y), g x, g x),
$$

which implies that $G_{1}(F(x, y), g x, g x)=0$, and so $F(x, y)=g x$. In a similar way, we can show that $F(y, x)=g y$. Hence, $(g x, g y)$ is a coupled point of coincidence of the mappings $F$ and $g$. Now, we shall show that $g x=g y$. In fact, from (2.21) we have

$$
\begin{aligned}
& G_{1}(g x, g y, g y) \\
& \quad=G_{1}(F(x, y), F(y, x), F(y, x)) \\
& \quad \leq k \max \left\{\begin{array}{c}
G_{2}(g x, g y, g y), G_{2}(g y, g x, g x), G_{2}(F(x, y), g y, g y), G_{2}(F(x, y), g x, g y), \\
\frac{1}{2} G_{2}\left((F(x, y), g x, g x), \frac{1}{2} G_{2}(F(y, x), g y, g y), \frac{1}{2} G_{2}(F(y, x), g y, g y),\right. \\
\frac{1}{2} G_{2}(F(y, x), g y, g y), \frac{1}{2} G_{2}(F(x, y), F(y, x), g y), \frac{1}{2} G_{2}(F(y, x), F(x, y), g y)
\end{array}\right\} \\
& =k \max \left\{G_{2}(g x, g y, g y), G_{2}(g y, g x, g x)\right\} \\
& \leq k \max \left\{G_{1}(g x, g y, g y), G_{1}(g y, g x, g x)\right\} .
\end{aligned}
$$

In the same way, we can show that

$$
G_{1}(g y, g x, g x) \leq k\left\{G_{1}(g y, g x, g x), G_{1}(g x, g y, g y)\right\} .
$$

If

$$
\max \left\{G_{1}(g x, g y, g y), G_{1}(g y, g x, g x)\right\}=G_{1}(g x, g y, g y),
$$

then by (2.29) we have $G_{1}(g x, g y, g y) \leq k G_{1}(g x, g y, g y)$. This implies that $G_{1}(g x, g y, g y)=0$, so that $g x=g y$. If

$$
\max \left\{G_{1}(g x, g y, g y), G_{1}(g y, g x, g x)\right\}=G_{1}(g y, g x, g x),
$$

then from (2.30) we obtain $G_{1}(g y, g x, g x) \leq k G_{1}(g y, g x, g x)$, which implies that $G_{1}(g y, g x$, $g x)=0$, so that $g x=g y$.

Therefore, $(g x, g x)$ is a coupled point of coincidence of mappings $F$ and $g$.

If there is another $x^{*} \in X$ such that $\left(g x^{*}, g x^{*}\right)$ is a coupled point of coincidence of mappings $F$ and $g$, then by (2.21) we get

$$
\begin{aligned}
& G_{1}\left(g x, g x^{*}, g x^{*}\right) \\
& =G_{1}\left(F(x, x), F\left(x^{\prime \prime}, x^{*}\right), F\left(x^{* \prime}, x^{*}\right)\right) \\
& \quad \leq k \max \left\{\begin{array}{c}
G_{2}\left(g x, g x^{*}, g x^{*}\right), G_{2}\left(g x, g x^{*}, g x^{*}\right), G_{2}\left(F(x, x), g x^{*}, g x^{*}\right), \\
G_{2}\left(F(x, x), g x, g x^{*}\right), \frac{1}{2} G_{2}\left((F(x, x), g x, g x), \frac{1}{2} G_{2}\left(F\left(x^{*}, x^{*}\right), g x^{\prime \prime}, g x^{*}\right),\right. \\
\frac{1}{2} G_{2}\left(F\left(x^{*}, x^{*}\right), g x^{*}, g x^{*}\right), \frac{1}{2} G_{2}\left(F\left(x^{*}, x^{*}\right), g x^{*}, g x^{*}\right), \\
\frac{1}{2} G_{2}\left(F(x, x), F\left(x^{*}, x^{*}\right), g x^{*}\right), \frac{1}{2} G_{2}\left(F\left(x^{*}, x^{*}\right), F(x, x), g x^{*}\right)
\end{array}\right\} \\
& =k \max \left\{G_{2}\left(g x, g x^{*}, g x^{*}\right), G_{2}\left(g x^{*}, g x, g x\right)\right\} \\
& \leq k \max \left\{G_{1}\left(g x, g x^{*}, g x^{*}\right), G_{1}\left(g x^{*}, g x, g x\right)\right\} .
\end{aligned}
$$


In the same way, we can show that

$$
G_{1}\left(g x^{*}, g x, g x\right) \leq k\left\{G_{1}\left(g x^{*}, g x, g x\right), G_{1}\left(g x, g x^{*}, g x^{*}\right)\right\} .
$$

If

$$
\max \left\{G_{1}\left(g x, g x^{*}, g x^{*}\right), G_{1}\left(g x^{*}, g x, g x\right)\right\}=G_{1}\left(g x, g x^{*}, g x^{*}\right),
$$

then by $(2.31)$ we have $G_{1}\left(g x, g x^{*}, g x^{\prime \prime}\right) \leq k G_{1}\left(g x, g x^{*}, g x^{*}\right)$. This implies that $G_{1}\left(g x, g x^{\prime \prime}, g x^{*}\right)=$ 0 , so that $g x=g x^{*}$. If

$$
\max \left\{G_{1}\left(g x, g x^{*}, g x^{*}\right), G_{1}\left(g x^{*}, g x, g x\right)\right\}=G_{1}\left(g x^{*}, g x, g x\right),
$$

then from (2.32) we obtain $G_{1}\left(g x^{*}, g x, g x\right) \leq k G_{1}\left(g x^{*}, g x, g x\right)$, which implies that $G_{1}\left(g x^{*}, g x\right.$, $g x)=0$, so that $g x=g x "$.

Thus, $(g x, g x)$ is a unique coupled point of coincidence of mappings $F$ and $g$.

Now we show that $F$ and $g$ have a unique common coupled fixed point. For this, let $g x=u$. Then we have $u=g x=F(x, x)$. By $w^{\prime \prime}$-compatibility of $F$ and $g$, we have

$$
g u=g(g x)=g F(x, x)=F(g x, g x)=F(u, u) .
$$

Thus, $(g u, g u)$ is a coupled point of coincidence of $F$ and $g$. By the uniqueness of a coupled point of coincidence, we have $g u=g x$. Therefore, $u=g u=F(u, u)$, that is, $(u, u)$ is the common coupled fixed point of $F$ and $g$.

To prove the uniqueness, let $v \in X$ with $v \neq u$ such that

$$
v=g v=F(v, v) \quad \text { and } \quad u=g u=F(u, u) .
$$

By using (2.21), following the same arguments as in the proof of (2.31) and (2.32), we obtain

$$
\begin{aligned}
G_{1}(u, v, v) & =G_{1}(g u, g v, g v) \leq k\left\{G_{1}(g u, g v, g v), G_{1}(g v, g u, g u)\right\} \\
& =k\left\{G_{1}(u, v, v), G_{1}(v, u, u)\right\}
\end{aligned}
$$

and

$$
\begin{aligned}
G_{1}(v, u, u) & =G_{1}(g v, g u, g u) \leq k\left\{G_{1}(g v, g u, g u), G_{1}(g u, g v, g x v)\right\} \\
& =k\left\{G_{1}(v, u, u), G_{1}(u, v, v)\right\} .
\end{aligned}
$$

If $\max \left\{G_{1}(u, v, v), G_{1}(v, u, u)\right\}=G_{1}(u, v, v)$, then by (2.33) we have $G_{1}(u, v, v) \leq k G_{1}(u, v, v)$, which implies that $G_{1}(u, v, v)=0$, so that $u=v$. If $\max \left\{G_{1}(u, v, v), G_{1}(v, u, u)\right\}=G_{1}(v, u, u)$, then from (2.34) we obtain $G_{1}(v, u, u) \leq k G_{1}(v, u, u)$, which implies that $G_{1}(v, u, u)=0$, so that $u=v$.

Thus, $(u, u)$ is a unique common coupled fixed point of mappings $F$ and $g$. This completes the proof of Theorem 2.11 . 
Remark 2.12 Theorem 2.11 improves and extends Theorem 2.6 of Abbas et al. [25] in the following aspects:

(1) The contractive condition defined by (1.2) is replaced by the new contractive condition defined by (2.21).

(2) The condition $0 \leq k<\frac{1}{2}$ is replaced by the new condition $0 \leq k<1$.

Corollary 2.13 Let $G_{1}$ and $G_{2}$ be two G-metrics on $X$ such that $G_{2}(x, y, z) \leq G_{1}(x, y, z)$ for all $x, y, z \in X$, and let $F: X \times X \rightarrow X, g: X \rightarrow X$ be two mappings satisfying

$$
\begin{aligned}
& G_{1}(F(x, y), F(u, v), F(s, t)) \\
& \quad \leq k \max \left\{G_{2}(g x, g u, g s), G_{2}(g y, g v, g t), G_{2}(F(x, y), g u, g s)\right\}
\end{aligned}
$$

for all $(x, y),(u, v),(s, t) \in X \times X$, where $0 \leq k<1$. If $F(X \times X) \subset g(X)$ and $g(X)$ is a $G_{1}$ complete subspace of $X$, and $F$ and $g$ are $w^{\prime \prime}$-compatible, then $F$ and $g$ have a unique common coupled fixed point.

Remark 2.14 Corollary 2.13 improves and extends Theorem 2.6 of Abbas et al. [25], the condition $0 \leq k<\frac{1}{2}$ is replaced by the new condition $0 \leq k<1$.

Next, we introduce two examples to support Corollary 2.13.

Example 2.15 Let us reconsider Example 2.1. For all $(x, y),(u, v),(s, t) \in X \times X$, we have

$$
\begin{aligned}
G_{1} & F(x, y), F(u, v), F(s, t)) \\
\quad & G_{1}\left(\frac{1}{16} x+\frac{5}{16} y, \frac{1}{16} u+\frac{5}{16} v, \frac{1}{16} s+\frac{5}{16} t\right) \\
& \leq \frac{1}{16}(|x-u|+|u-s|+|s-x|)+\frac{5}{16}(|y-v|+|v-t|+|t-y|) \\
& =\frac{5}{32} \cdot \frac{4}{5}(|g x-g u|+|g u-g s|+|g s-g x|)+\frac{25}{32} \cdot \frac{4}{5}(|g y-g v|+|g v-g t|+|g t-g y|) \\
& =\frac{5}{32} G_{2}(g x, g u, g s)+\frac{25}{32}(g y, g v, g t) \\
& \leq\left(\frac{5}{32}+\frac{25}{32}\right) \max \left\{G_{2}(g x, g u, g s),(g y, g v, g t)\right\} \\
& \leq \frac{15}{16} \max \left\{G_{2}(g x, g u, g s), G_{2}(g y, g v, g t), G_{2}(F(x, y), g u, g s)\right\} .
\end{aligned}
$$

Then the statement (2.35) of Corollary 2.13 is satisfied for $k=\frac{15}{16}$. Other assumptions of Corollary 2.13 are easy to verify. So, by Corollary 2.13, there exists a unique $x \in X$ such that $g x=F(x, x)=x$. In fact, it is easy to see that $(0,0)$ is the unique common coupled fixed point of $F$ and $g$.

Example 2.16 Let $X=[0,1]$. Define $G_{1}, G_{2}: X \times X \times X \rightarrow[0, \infty)$ by

$$
G_{1}(x, y, z)=|x-y|+|y-z|+|z-x| \quad \text { and } \quad G_{2}(x, y, z)=\frac{4}{5}(|x-y|+|y-z|+|z-x|)
$$


for all $x, y, z \in X$. Then $\left(X, G_{1}\right)$ and $\left(X, G_{2}\right)$ are two $G$-metric spaces. Define a map $F: X \times$ $X \rightarrow X$ by $F(x, y)=1-\frac{1}{8} x-\frac{5}{8} y$ and $g x=x$ for all $x, y \in X$. We have

$$
\begin{aligned}
G_{1} & (F(x, y), F(u, v), F(s, t)) \\
& =G_{1}\left(1-\frac{1}{8} x-\frac{5}{8} y, 1-\frac{1}{8} u-\frac{5}{8} v, 1-\frac{1}{8} s-\frac{5}{8} t\right) \\
& \leq \frac{1}{8}(|x-u|+|u-s|+|s-x|)+\frac{5}{8}(|y-v|+|v-t|+|t-y|) \\
& =\frac{5}{32} G_{2}(g x, g u, g s)+\frac{25}{32}(g y, g v, g t) \\
& \leq\left(\frac{5}{32}+\frac{25}{32}\right) \max \left\{G_{2}(g x, g u, g s),(g y, g v, g t)\right\} \\
& \leq \frac{15}{16} \max \left\{G_{2}(g x, g u, g s), G_{2}(g y, g v, g t), G_{2}(F(x, y), g u, g s)\right\} .
\end{aligned}
$$

Then the statement (2.35) of Corollary 2.13 is satisfied for $k=\frac{15}{16}$. Other assumptions of Corollary 2.13 are easy to verify. So, by Corollary 2.13, there exists a unique $x \in X$ such that $g x=F(x, x)=x$. In fact, $g\left(\frac{4}{7}\right)=F\left(\frac{4}{7}, \frac{4}{7}\right)=\frac{4}{7}$.

Remark 2.17 Theorem 1.8 cannot be applied to Example 2.16 since (1.2) does not hold. In fact, if (1.2) holds for some $k \in\left[0, \frac{1}{2}\right)$, then

$$
\begin{aligned}
1 & =G_{1}\left(\frac{3}{8}, \frac{7}{8}, \frac{7}{8}\right) \\
& =G_{1}(F(0,1), F(1,0), F(1,0)) \\
& \leq k \max \left\{G_{2}(g 0, g 1, g 1), G_{2}(g 1, g 0, g 0), G_{2}(F(0,1), g 1, g 1)\right\} \\
& =k \max \left\{G_{2}(0,1,1), G_{2}(1,0,0), G_{2}\left(\frac{3}{8}, 1,1\right)\right\} \\
& =k \max \left\{\frac{8}{5}, \frac{8}{5}, \frac{4}{5} \cdot \frac{5}{4}\right\} \\
& =\frac{8}{5} k<\frac{4}{5},
\end{aligned}
$$

which is a contradiction.

Corollary 2.18 Let $G_{1}$ and $G_{2}$ be two G-metrics on $X$ such that $G_{2}(x, y, z) \leq G_{1}(x, y, z)$ for all $x, y, z \in X$, and let $F: X \times X \rightarrow X, g: X \rightarrow X$ be two mappings satisfying

$$
G_{1}(F(x, y), F(u, v), F(s, t)) \leq k \max \left\{\begin{array}{c}
G_{2}(g x, g u, g s), G_{2}(g y, g v, g t), \\
G_{2}(F(x, y), g u, g s), G_{2}(F(x, y), g x, g u)
\end{array}\right\}
$$

for all $(x, y),(u, v),(s, t) \in X \times X$, where $0 \leq k<1$. If $F(X \times X) \subset g(X)$ and $g(X)$ is a $G_{1}$ complete subspace of $X$, and $F$ and $g$ are $w^{*}$-compatible, then $F$ and $g$ have a unique common coupled fixed point. 
Corollary 2.19 Let $G_{1}$ and $G_{2}$ be two G-metrics on $X$ such that $G_{2}(x, y, z) \leq G_{1}(x, y, z)$ for all $x, y, z \in X$, and let $F: X \times X \rightarrow X, g: X \rightarrow X$ be two mappings satisfying

$$
\begin{aligned}
& G_{1}(F(x, y), F(u, v), F(s, t)) \\
& \quad \leq k \max \left\{\begin{array}{c}
G_{2}\left((F(x, y), g x, g x), G_{2}(F(u, v), g u, g u),\right. \\
G_{2}(F(s, t), g s, g s), G_{2}(F(u, v), g u, g s), \\
G_{2}(F(x, y), F(u, v), g s), G_{2}(F(s, t), F(x, y), g u)
\end{array}\right\}
\end{aligned}
$$

for all $(x, y),(u, v),(s, t) \in X \times X$, where $0 \leq k<\frac{1}{2}$. If $F(X \times X) \subset g(X)$ and $g(X)$ is a $G_{1}$ complete subspace of $X$, and $F$ and $g$ are $w^{*}$-compatible, then $F$ and $g$ have a unique common coupled fixed point.

Remark 2.20 Theorem 2.2 and Corollaries 2.5-2.10 improve and extend Theorems 2.2, 2.5, 2.6, Corollary 2.3, 2.7 and 2.8 of Sabetghadam et al. [23].

\section{Competing interests}

The author declares that they have no competing interests.

\section{Acknowledgements}

The author is grateful to the editor and the reviewer for suggestions which improved the contents of the article. This work is supported by the National Natural Science Foundation of China (11271105) and the Natural Science Foundation of Zhejiang Province (Y6110287, LY12A01030).

Received: 27 December 2012 Accepted: 26 June 2013 Published: 11 July 2013

\section{References}

1. Mustafa, Z, Sims, B: A new approach to a generalized metric space. J. Nonlinear Convex Anal. 7(2), $289-297$ (2006)

2. Mustafa, Z, Obiedat, H, Awawdeh, F: Some fixed point theorems for mappings on complete G-metric space. Fixed Point Theory Appl. 2008, Article ID 189870 (2008). doi:10.1155/2008/189870

3. Mustafa, Z, Shatanawi, W, Bataineh, M: Existence of fixed points results in G-metric spaces. Int. J. Math. Math. Sci. 2009, Article ID 283028 (2009)

4. Mustafa, Z, Sims, B: Fixed point theorems for contractive mappings in complete G-metric spaces. Fixed Point Theory Appl. 2009, Article ID 917175 (2009)

5. Mustafa, Z, Awawdeh, F, Shatanawi, W: Fixed point theorem for expansive mappings in G-metric spaces. Int. J. Contemp. Math. Sci. 5(50), 2463-2472 (2010)

6. Mustafa, Z, Khandagji, M, Shatanawi, W: Fixed point results on complete G-metric spaces. Studia Sci. Math. Hung. 48(3), 304-319 (2011)

7. Chugh, R, Kadian, T, Rani, A, Rhoades, BE: Property P in G-metric spaces. Fixed Point Theory Appl. 2010, Article ID 401684 (2010)

8. Shatanawi, W: Fixed point theory for contractive mappings satisfying $\Phi$-maps in G-metric spaces. Fixed Point Theory Appl. 2010, Article ID 181650 (2010)

9. Abbas, M, Rhoades, BE: Common fixed point results for noncommuting mappings without continuity in generalized metric spaces. Appl. Math. Comput. 215(1), 262-269 (2009)

10. Abbas, M, Nazir, T, Saadati, R: Common fixed point results for three maps in generalized metric space. Adv. Differ. Equ. 49, 1-20 (2011)

11. Abbas, M, Khan, SH, Nazir, T: Common fixed points of $R$-weakly commuting maps in generalized metric spaces. Fixed Point Theory Appl. 2011, Article ID 784595 (2011)

12. Abbas, $M$, Nazir, T, Dorić, D: Common fixed point of mappings satisfying ( $E . A)$ property in generalized metric spaces. Appl. Math. Comput. 218(14), 7665-7670 (2012)

13. Mustafa, Z, Aydi, H, Karapinar, E: On common fixed points in G-metric spaces using (E.A) property. Comput. Math. Appl. 64(6), 1944-1956 (2012)

14. Ye, H, Gu, F: Common fixed point theorems for a class of twice power type contraction maps in G-metric spaces. Abstr. Appl. Anal. 2012, Article ID 736214 (2012)

15. Gu, F: Common fixed point theorems for six mappings in generalized metric spaces. Abstr. Appl. Anal. 2012, Article ID 379212 (2012). doi:10.1155/2012/379212

16. Gu, F, Ye, H: Common fixed point theorems of Altman integral type mappings in G-metric spaces. Abstr. Appl. Anal. 2012, Article ID 630457 (2012). doi:10.1155/2012/630457

17. Long, W, Abbas, M, Nazir, T, Radenović, S: Common fixed point for two pairs of mappings satisfying (E.A) property in generalized metric spaces. Abstr. Appl. Anal. 2012, Article ID 394830 (2012). doi:10.1155/2012/394830

18. Tahat, N, Aydi, H, Karapinar, E, Shatanawi, W: Common fixed points for single-valued and multi-valued maps satisfying a generalized contraction in G-metric spaces. Fixed Point Theory Appl. 2012, 48 (2012).

doi:10.1186/1687-1812-2012-48 
19. Mustafa, Z: Some new common fixed point theorems under strict contractive conditions in G-metric spaces. J. Appl. Math. 2012, Article ID 248937 (2012). doi:10.1155/2012/248937

20. Bhaskar, TG, Lakshmikantham, V: Fixed point theorems in partially ordered metric spaces and applications. Nonlinear Anal. 65, 1379-1393 (2006)

21. Lakshmikantham, V, Ćirić, L: Coupled fixed point theorems for nonlinear contractions in partially ordered metric spaces. Nonlinear Anal. 70, 4341-4349 (2009)

22. Abbas, M, Khan, MA, Radenović, S: Common coupled fixed point theorem in cone metric space for $w$-compatible mappings. Appl. Math. Comput. 217, 195-202 (2010). doi:10.1016/j.amc.2010.05.042

23. Sabetghadam, F, Masiha, HP, Sanatpour, AH: Some coupled fixed point theorems in cone metric spaces. Fixed Point Theory Appl. 2009, Article ID 125426 (2009)

24. Shatanawi, S: Coupled fixed point theorems in generalized metric spaces. Hacet. J. Math. Stat. 40(3), $441-447$ (2011)

25. Abbas, M, Khan, AR, Nazir, T: Coupled common fixed point results in two generalized metric spaces. Appl. Math. Comput. 217, 6328-6336 (2011). doi:10.1016/j.amc.2011.01.006

26. Shatanawi, W, Abbas, M, Nazir, T: Common coupled coincidence and coupled fixed point results in two generalized metric spaces. Fixed Point Theory Appl. 2011, 80 (2011). doi:10.1186/1687-1812-2011-80

27. Gu, F, Zhou, S: Coupled common fixed point theorems for a pair of commuting mappings in partially ordered G-metric spaces. Fixed Point Theory Appl. 2013, 64 (2013). doi:10.1186/1687-1812-2013-64

28. Saadati, R, Vaezpour, SM, Vetro, P, Rhoades, BE: Fixed point theorems in generalized partially ordered G-metric spaces. Math. Comput. Model. 52(5-6), 797-810 (2010)

29. Choudhury, BS, Maity, P: Coupled fixed point results in generalized partially ordered G-metric spaces. Math. Comput. Model. 54, 73-79 (2011)

30. Aydi, H, Damjanović, B, Samet, B, Shatanawi, W: Coupled fixed point theorems for nonlinear contractions in partially ordered G-metric spaces. Math. Comput. Model. 54(9-10), 2443-2450 (2011)

31. Shatanawi, W: Some fixed point theorems in ordered G-metric spaces and applications. Abstr. Appl. Anal. 2011, Article ID 126205 (2011). doi:10.1155/2011/126205

32. Luong, NV, Thuan, NX: Coupled fixed point theorems in partially ordered G-metric spaces. Math. Comput. Model. 55(3-4), 1601-1609 (2012)

33. Aydi, H, Postolache, M, Shatanawi, W: Coupled fixed point results for $(\psi, \varphi)$-weakly contractive mappings in ordered G-metric spaces. Comput. Math. Appl. 63(1), 298-309 (2012)

34. Abbas, M, Nazir, T, Radenović, S: Common fixed point of generalized weakly contractive maps in partially ordered G-metric spaces. Appl. Math. Comput. 218(18), 9383-9395 (2012)

35. Cho, YJ, Rhoades, BE, Saadati, R, Samet, B, Shatanawi, W: Nonlinear coupled fixed point theorems in ordered generalized metric spaces with integral type. Fixed Point Theory Appl. 2012, 8 (2012). doi:10.1186/1687-1812-2012-8

36. Abbas, M, Sintunavarat, W, Kumam, P: Coupled fixed point of generalized contractive mappings on partially ordered G-metric spaces. Fixed Point Theory Appl. 2012, 31 (2012). doi:10.1186/1687-1812-2012-31

37. Mustafa, Z, Aydi, H, Karapmar, E: Mixed $g$-monotone property and quadruple fixed point theorems in partially ordered metric space. Fixed Point Theory Appl. 2012, 71 (2012). doi:10.1186/1687-1812-2012-71

38. Razani, A, Parvaneh, V: On generalized weakly G-contractive mappings in partially ordered G-metric spaces. Abstr. Appl. Anal. 2012, Article ID 701910 (2012). doi:10.1155/2012/701910

doi:10.1186/1687-1812-2013-181

Cite this article as: Gu: Some new common coupled fixed point results in two generalized metric spaces. Fixed Point Theory and Applications 2013 2013:181

\section{Submit your manuscript to a SpringerOpen ${ }^{\odot}$ journal and benefit from:}

- Convenient online submission

- Rigorous peer review

- Immediate publication on acceptance

- Open access: articles freely available online

- High visibility within the field

- Retaining the copyright to your article 